\title{
Maintaining weight loss: an ongoing challenge
}

Priya Sumithran MBBS, FRACP, PhD and Joseph Proietto MBBS, FRACP, PhD

University of Melbourne, Department of Medicine (Austin Health), Melbourne, Australia

\section{Correspondence:}

Dr Priya Sumithran

Level 2, Boronia Centre

Repatriation Hospital

300 Waterdale Rd

Heidelberg, VIC, 3081

Australia

priyas@unimelb.edu.au

Tel: +61 394962250

Fax: +61 394974554

Article type: invited commentary

Keywords: obesity, weight loss, adaptations, energy expenditure

Word count: 1436 
For most people with obesity who have lost a substantial amount of weight, maintaining that weight loss takes at least as much effort as losing the weight to begin with. Despite their intentions to the contrary, the majority of people will eventually regain most, if not all, of the weight that they managed to lose [1]. Why is this so?

A recent paper from Fothergill and colleagues [2], reporting long-term data from participants in the televised "Biggest Loser" weight loss competition, adds to the growing evidence that weight reduction brings about biological adaptations which favour weight regain. This study examined body composition, energy expenditure and biochemical parameters in 14 of the 16 people with severe obesity who had taken part in "Biggest Loser" competition 6 years earlier. While housed together, contestants performed 90 minutes of supervised vigorous circuit and/or aerobic training 6 days per week, and additional exercise of up to 3 hours per day was encouraged. They were also advised to restrict their dietary energy intake to at least $70 \%$ of estimated baseline requirements. Every 7-10 days, one participant was sent home, and all remaining contestants returned home after week 13, to continue their weight loss program unsupervised until the end of the competition at week 30 [3]. At the start of the contest, mean ( \pm SD) weight of the 14 participants was $148.9 \pm 40.5 \mathrm{~kg}$ (BMI $49.5 \pm 10.1 \mathrm{~kg} / \mathrm{m}^{2}$ ). Over the 30 week competition, mean weight loss was $58.3 \pm 24.9 \mathrm{~kg}$, and 6 years later, a mean of 41.0 $\pm 31.3 \mathrm{~kg}$ had been regained. Measured resting metabolic rate (RMR) fell from $2607 \pm 649$ $\mathrm{kcal} /$ day at baseline to $1996 \pm 358 \mathrm{kcal} /$ day by week 30 , and despite considerable weight regain 6 years later, the reduction in RMR was sustained $(1903 \pm 466 \mathrm{kcal} /$ day $)$. The most notable finding of this study was that measured RMR was $275 \mathrm{kcal} /$ day lower than predicted for changes in body composition and age at week 30, and this gap ("metabolic adaptation") increased to $499 \mathrm{kcal} /$ day at 6 years. The degree of metabolic adaptation at 6 years (but not 30 weeks) correlated with \% weight regain [2].

While it could be argued that the extreme intensity of the exercise and diet regimen undertaken by the "Biggest Loser" contestants makes these findings difficult to extrapolate to less rigorous weight loss interventions, the results are in accordance with other studies in which metabolic adaptation has been documented after more moderate weight loss. A 10\% reduction in body weight due to dietary restriction is accompanied by a reduction in total energy expenditure (TEE) to a level $15 \%$ below that which can be accounted for by alterations in body mass and composition in both lean and obese people [4], and this disproportionate decline in TEE persists for at least one year of maintenance of the reduced body weight [5]. In a recent reanalysis of data from their previous inpatient metabolic studies [6], Rosenbaum and Leibel concluded that the decline in TEE with 10\% weight loss reflects roughly equivalent reductions in resting and non-resting energy expenditure, whereas the continuing fall in TEE during a further $10 \%$ (i.e. total 20\%) weight loss is contributed to primarily by changes in non-resting energy expenditure.

Several studies have indicated that compensatory changes as a result of diet-induced weight reduction occur not only in energy expenditure, but also in circulating concentrations of a multitude of hormones involved in appetite regulation, almost all of which counteract weight loss. For example, leptin, a "satiety hormone" usually released from adipocytes in proportion to fat mass as an indicator of the adequacy of energy stores, decreases profoundly in response to negative energy imbalance. After 30 weeks of the "Biggest Loser" competition, participants' body fat percentage reduced from 49 to $28 \%$, while leptin fell from 41.14 to $2.56 \mathrm{ng} / \mathrm{mL}$ [2]. Other hormonal perturbations resulting from diet-induced weight loss include increases in the hunger-stimulating hormone ghrelin, reductions in the satiety hormones peptide YY (PYY), cholecystokinin and amylin, and suppression of the 
hypothalamic-pituitary-thyroid axis [3, 7-11]. Collectively, these changes favour weight regain, and like metabolic adaptation, largely persist well beyond the initial period of weight loss $[2,5,7]$. In keeping with the expected effect of the hormonal changes, a sustained increase in subjective appetite has been described after diet-induced weight-loss [7, 12], and interestingly, there is evidence of increases not only in ratings for aspects of appetite such as hunger and desire to eat [7, 12], but also in the perceived rewarding properties of food [13] and a preference for high-calorie food [14]. Furthermore, studies in which functional brain imaging techniques have been used to examine brain activity patterns in response to food stimuli have demonstrated changes after diet-induced weight loss in people with obesity including increased neural activity in the limbic (reward) system, and reduced activity in areas involved in the emotional control of food intake after weight loss compared to preweight loss [15].

The adaptive responses to weight loss appear to be related to the amount of weight lost $[2,3$, 6], rather than the rate at which it is lost. Fasting plasma leptin and total ghrelin are not significantly different between groups of people who achieved comparable weight reductions rapidly (using a very-low-energy diet) or gradually (with a hypocaloric diet) [16], and many elements of the compensatory response are reversed if leptin is administered to replicate preweight loss levels $[11,15]$. Studies have also found no difference in the amount and rate of weight regain if an equivalent amount of weight is lost rapidly or gradually $[16,17]$.

If there is a biological response which counteracts weight loss, what does this mean for people with obesity who wish to lose weight? Is it futile to attempt to do so? We do not believe so, for several reasons:

1. Modest (5-10\%) weight loss confers significant reductions in the risks of several weightrelated conditions such as type 2 diabetes, obstructive sleep apnoea, non-alcoholic fatty liver disease [18], and is likely to be accompanied by milder metabolic adaptation.

2. Although the majority of people will eventually regain much of the lost weight, results are variable, and a proportion of people manage to maintain clinically beneficial weight losses over the long-term. Despite returning to their usual environment without any ongoing support after the unsustainably rigorous initial diet and exercise phase, the "Biggest Loser" contestants were a mean of $12 \%(17 \mathrm{~kg})$ below their starting weight 6 years after the competition [2]. More than 4000 U.S. adults in the National Weight Control Registry database (97\% Caucasian, 80\% women) have maintained a loss of at least $13.6 \mathrm{~kg}$ (30 lbs) for a mean of over 5 years [19]. The majority of registry members report undertaking a number of strategies to prevent weight regain, such as consistently eating a low-calorie, low-fat diet with minimal variation, frequent self-monitoring (e.g. self-weighing, calorie-counting), and undertaking high levels of physical activity [19].

3. Medications which reduce hunger may help adherence to behaviour change. Since 2012, four such agents have been approved by the U.S. Food and Drug Administration for chronic weight management: lorcaserin (Belviq), the combination of phentermine and topiramate extended-release (Qsymia), the GLP-1 analogue liraglutide 3mg (Saxenda) and combination naltrexone/bupropion (Contrave) [20]. Although at present, all are indicated for induction of weight loss and it is recommended to discontinue their use if weight loss of $\geq 5 \%$ does not occur within 3 months, we believe that prevention of weight regain after weight loss achieved through dietary change, exercise and behavioural modification is another valuable potential application of pharmacotherapy which deserves exploration.

4. In contrast to the appetite and gut hormone changes seen with diet-induced weight loss, bariatric surgery facilitates control of hunger during weight reduction, and the procedures of 
Roux-en-Y gastric bypass (RYGB) and sleeve gastrectomy bring about a gut hormone profile which favours a decrease in appetite [21].

In summary, recent studies have contributed to the growing understanding that a multitude of physiological adaptations counteract weight reduction, many of which persist well beyond the initial weight loss period, even after a considerable proportion of weight has been regained. This would be advantageous during prolonged interruptions in food supply, but in an "obesogenic" environment of plentiful high-calorie food, these adaptations are an impediment for people attempting to lose a considerable amount of weight, most of whom will regain weight over time. People with obesity who have taken the steps required to lose weight do not regain it due to a lack of diligence, willpower or motivation. Like other chronic conditions, obesity is not "cured" after the phase of treatment (weight loss), and strategies for long-term management (maintenance of weight loss) are required.

Conflicts of Interest: PS has received speaker honoraria from Nestlé and Novo Nordisk. JP is chair of the Medical Advisory Board for Saxenda (Australia, Novo Nordisk) and has received speaker honoraria for iNova and Nestlé.

\section{REFERENCES}

1 Anderson J, Konz E, Frederich R and Wood C. Long-term weight-loss maintenance: a meta-analysis of US studies. Am J Clin Nutr. 2001;74:579-84

2 Fothergill E, Guo J, Howard L et al Persistent metabolic adaptation 6 years after "The Biggest Loser" competition. Obesity 2016;24:1612-9

3 Johannsen D, Knuth N, Huizenga R et al.Metabolic slowing with massive weight loss despite preservation of fat-free mass. J Clin Endocrinol Metab 2012;97:2489-96

$4 \quad$ Leibel R, Rosenbaum M and Hirsch J.Changes in energy expenditure resulting from altered body weight. N Engl J Med 1995;332:6218

5 Rosenbaum M, Hirsch J, Gallagher D and Leibel R. Long-term persistence of adaptive thermogenesis in subjects who have maintained a reduced body weight. Am J Clin Nutr 2008;88:906-12

6 Rosenbaum M and Leibel R. Models of energy homeostasis in response to maintenance of reduced body weight. Obesity 2016;24:1620-9

$7 \quad$ Sumithran P, Prendergast L, Delbridge E et al. Long-term persistence of hormonal adaptations to weight loss. N Engl J Med 2011;365:1597-604

8 Chearskul S, Delbridge E, Shulkes A et al. Effect of weight loss and ketosis on postprandial cholecystokinin and free fatty acid concentrations. Am J Clin Nutr 2008;87:1238-46

9 Cummings D, Weigle D, Frayo R et al. Plasma ghrelin levels after diet-induced weight loss or gastric bypass surgery. N Engl J Med 2002;346:1623-30

10 Pfluger P, Kampe J, Castaneda T et al. Effect of human body weight changes on circulating levels of peptide YY and peptide YY3-36. J Clin Endocrinol Metab 2007;92:5838

11 Rosenbaum M, Goldsmith R, Bloomfield D et al. Low-dose leptin reverses skeletal muscle, autonomic, and neuroendocrine adaptations to maintenance of reduced weight. J Clin Invest 2005;115:3579-86

12 Doucet E, Imbeault P, St-Pierre $S$ et al. Appetite after weight loss by energy restriction and a low-fat diet-exercise follow-up. Int J Obes Relat Metab Disord 2000;24:90614 
13 Cameron, J, Goldfield G, Cyr M-J and Doucet E. The effects of prolonged caloric restriction leading to weight-loss on food hedonics and reinforcement. Physiol Behav 2008;94:474-80

14 Drewnowski A, Brunzell J, Sande K et al. Sweet tooth reconsidered: taste responsiveness in human obesity. Physiol Behav. 1985;35:617-22

15 Rosenbaum M, Sy M, Pavlovich K et al. Leptin reverses weight loss-induced changes in regional neural activity responses to visual food stimuli. J Clin Invest. 2008;118:2583-91

16 Purcell K, Sumithran P, Prendergast L et al. The effect of rate of weight loss on longterm weight management: a randomised controlled trial. Lancet Diabetes Endocrinol 2014;2:954-62

17 Vink R, Roumans N, Arkenbosch L et al. The effect of rate of weight loss on longterm weight regain in adults with overweight and obesity. Obesity 2016;24:321-7

18 Jensen M, Ryan D, Apovian C et al. 2013 AHA/ACC/TOS guideline for the management of overweight and obesity in adults: a report of the American College of Cardiology/American Heart Association Task Force on Practice Guidelines and The Obesity Society. Circ 2014;129 (25 Suppl 2):S102-138.

19 Wyatt H, Phelan S, Wing R and Hill J. Lessons from patients who have successfully maintained weight loss. Obesity Management 2005;1:56-61

20 Apovian C, Aronne L, Bessesen D et al. Pharmacological management of obesity: an Endocrine Society Clinical Practice Guideline. J Clin Endocrinol Metab 2015; 100:342-62

21 Peterli R, Steinert R, Woelnerhanssen B et al. Metabolic and hormonal changes after laparoscopic Roux-en-Y gastric bypass and sleeve gastrectomy: a randomized, prospective trial. Obes Surg 2012;22:740-8 


\section{University Library}

\section{- M M I E R R V A gateway to Melbourne's research publications}

Minerva Access is the Institutional Repository of The University of Melbourne

Author/s:

Sumithran, P;Proietto, J

Title:

Maintaining Weight Loss: an Ongoing Challenge

Date:

2016-12-01

Citation:

Sumithran, P. \& Proietto, J. (2016). Maintaining Weight Loss: an Ongoing Challenge.

CURRENT OBESITY REPORTS, 5 (4), pp.383-385. https://doi.org/10.1007/

s13679-016-0230-y.

Persistent Link:

http://hdl.handle.net/11343/123867 